\title{
Effect of administrative information on visit rate of frequent attenders in primary health care: ten-year follow-up study
}

\author{
Anne K. Santalahti ${ }^{1 *}$, Tero J. Vahlberg ${ }^{2}$, Sinikka H. Luutonen ${ }^{3,4}$ and Päivi T. Rautava, ${ }^{5,6}$
}

\begin{abstract}
Background: Frequent attenders (FAs) use a disproportionately large share of the resources of general practitioners (GPs) working in primary healthcare centres. The aim of this study was to estimate the proportion of FAs among all patients in the primary health care centres of a medium-sized city in Finland, and to examine whether providing GPs with administrative information about their frequent attenders (names and numbers of visits per year) can reduce the number of FAs and the frequency of their visits.
\end{abstract}

Methods: Statistic data on all GP visits ( $n=1.8$ million) to 11 public healthcare centres in one city were collected from the electronic patient records covering the period from 2001 to 2010. A FA-patient was defined as a person who made10 or more visits to GPs during one year. The baseline situation in 2001 was compared with the situation in 2006 after administrative information had been provided three times to all GPs working in the healthcare centres. Poisson's regression analysis was used, and FA numbers and consultation rates in the years 2002-2005 were compared with the year 2006; figures for 2006 were also compared with those for the follow-up period 2007-2010.

Results: During the years 2001-2006, the proportion of visits of FA-patients fell overall from 9.1 to $8.5 \%$, a decline of 0. $6 \%(p<0.0001)$. This reduction was equivalent to an annual work load of two GPs in the study center. The proportion of visits of FA patients increased again in the follow-up period (2007-2010), when administrative information was no longer provided.

Conclusion: When GPs are provided with information on the number and names of their FA-patients, the annual rate of FA visits to GPs drops significantly. The method is simple and repeatable. However, without a control group of GPs who have not received such information, it is impossible to assess if the intervention was the only circumstance affecting the reduction in FA consultation rates.

Keywords: Primary care, Frequent attenders, Administrative information, GP's work load

\section{Background}

There is no generally accepted definition of a frequent attender (FA). Most studies have used the number of visits per year as the criterion, but the specific number chosen to define a frequent attender varies widely, from 5 visits per year at one end of the range to 20 visits at the other [1-7]. There are studies where FAs are defined as patients who have one-year attendance rates, adjusted for age and gender, above the 90th percentile $[8,9]$. In

\footnotetext{
* Correspondence: anne.santalahti@ylojarvi.fi

${ }^{1}$ Turku City Healthcare Center, Turku, Finland

Full list of author information is available at the end of the article
}

Finnish studies, numerical definitions varying from at 8 to 11 GP visits per year have been generally used $[1-4,10]$.

The problem of frequent attenders has been studied for more than 60 years. Backett et al. reported in 1954 that $16 \%$ of patients made ten or more visits per year to general practitioners (GPs), and that these patients represented $52 \%$ of GPs' workload [11]. Frequent consulters are a small proportion of all GPS' patients but account for a disproportionate number of consultations [7]. Vedsted and Christiansen conducted a literature review in 2005, which found that the top $10 \%$ of attenders accounted for $30-50 \%$ of all GP contacts [12]. It is entirely acceptable to spend a lot of healthcare resources on patients whose

(C) The Author(s). 2018 Open Access This article is distributed under the terms of the Creative Commons Attribution 4.0 International License (http://creativecommons.org/licenses/by/4.0/), which permits unrestricted use, distribution, and 
condition demands it, but certain FAs can create unnecessary and unwelcome work and cause frustration for GPs [13].

Research by Heywood et al. (1998) found that FAs received many more prescriptions and were referred to hospital much often that other patients [14]; it is impossible to establish whether these treatment decisions were warranted by the condition of the patients concerned, or whether they represented poor use of healthcare resources. It has been estimated that a decrease of one visit per FA patient per year would decrease the average workload of a GP by $1 \%$ [14]. In Finland, the average frequency of visits to a GP decreased from 1.92 visits to 1.56 visit per inhabitant per year in the period from 2001 to 2010. One FA makes 10 or more visits to a GP per year, so the difference is considerable.

Systematic reviews indicate that FAs often have chronic diseases or other chronic physical or mental problems [4, 12, 15-17], and that they may also have long-lasting somatization and many concomitant disorders $[10,18]$. The majority of FAs are elderly females $[3,19,20]$. FAs' socioeconomic status is usually low and they use many social services [12]. Other characteristics are a body mass index over 30, fear of death, low alcohol intake, low satisfaction with healthcare services and irritable bowel syndrome [3].

Studies have been conducted to investigate what kind of interventions might reduce FAs' consultation rates. Research by Bellón et al. showed that intervention with GPs can be effective; in their study, three GPs received $15 \mathrm{~h}$ ' intervention training which incorporated biopsychosocial, organizational and rational approaches [21]. Jiwa tried to reduce Fas' consultation rates by giving GPs summarized notes on their Fas' medical histories which they could refer to during consultations but this intervention was not successful [22].

The present study was conducted in the city of Turku, which is the sixth largest city in Finland, with 175,000 to 178,000 inhabitants during the years of the study (20012010). Turku is an industrial and university city, with an immigrant population of about $8 \%$ and an age distribution similar to most industrialized countries. GPs have a capitation-based contract, where each GP is responsible for about 1500-2700 inhabitants, with a mean of 2312 inhabitants per GP in 2010. Usually, patients first call a nurse, who assesses the type of treatment needed and, if necessary, arranges an appointment with the allocated GP. In this Finnish primary care model, nurses thus control access to GPs to some extent, and as a result FAs do not meet their GPs as often as in many other countries. The duration of GP consultations varies from 10 to $45 \mathrm{~min}$.

The first aim of this study was to establish the total number of FA patients, and how many visits FAs made to the healthcare centres and primary care emergency clinic in Turku in 2001-2010. The second aim was to explore how administrative information provided to each GP about his/her FAs (names and number of visits for each FA in the preceding year) affects frequency of attendance. The hypothesis was that this simple intervention reduces frequent attendance by drawing the attention of GPs to the issue. Thirdly, for the years 20012010 , we compared the overall workload of the GPs in the study with the workload arising specifically from consultations with FAs. We also asked the GPs to draw up treatment plans for their patients listed as FAs in 2004, and we checked later to see how many plans had in fact been made.

\section{Methods}

The research design in this study is a registry-based cohort study. We used the developmental work research method; this model proceeds from evaluation of current action, to model and analysis of novel courses of action, to implementation and final assessment of the new courses of action [23]. In this study, FAs are defined as patients with 10 or more face-to-face visits to a GP during 1 year. The study population was formed by all patients who visited a GP ten times or more per year. The study data were retrieved from the electronic patient record system $\left(\right.$ Pegasos $^{\circ}$ ) of the city of Turku, where the research was conducted. The electronic patient record system was used by every GP in all of the 11 public healthcare centres in the city and in the primary care emergency clinic during the whole period of 2001-2010. Data were collected on all face-to-face visits to GPs, both in the healthcare centres and the emergency clinic.

In 2002-2005, the chief medical officer of the city of Turku held three short administrative information sessions during regular management meetings with all GPs. In the 2002 session, all the GPs received personalized information about the number of FAs identified in their own patient register for the previous calendar year (2001). The same procedure was repeated in 2003 concerning the data for 2002. In 2005, the list of FAs was updated again according to data covering the year 2004, and the information was passed to GPs as before. In addition, in the 2005 session, the chief medical officer asked the GPs to make treatment plans for the FAs on the 2004 list.

In 2006-2010 the data of the number of FA visits to GPs were collected but in this period, the information was not passed on to GPs. To estimate the impact of providing GPs with administrative information on FAs, we compared the number of FAs and the total number of FA visits in the starting year (2001) with the corresponding figures in 2002-2006. The results are expressed as relative risks (RR) with 95\% confidence intervals (95\% $\mathrm{CI})$. Then we analyzed the number of FAs and total FA 
visits in 2007-2010, i.e., over a period when the GPs had not received personalized information about their FAs. Finally, we compared those figures with the ones of 2006. The year 2006 was chosen as the comparison year because the final administrative information session for the GPs had been held in 2005.

The records of all patients listed as FAs in 2004 were checked during the follow-up period to see whether treatment plans had been made for them by their GPS. The number of treatment plans made was recorded.

Information on the number of GPs in 2001-2010, the number of days worked by each GP and the number of individual patients treated per workday was retrieved form the electronic patient record system.

The changes in the number of FA visits as a proportion of all visits to GPs were analyzed using Poisson's regression analysis over the whole period of 2001 to 2010. The natural logarithm of number of all visits to GPs' surgeries was used as an offset parameter in the Poisson model. The results were expressed as risk ratios (RR) with $95 \%$ confidence intervals ( $95 \% \mathrm{CI}) . P$-values of less than 0.05 were considered statistically significant. Statistical analyses were carried out using the SAS system for Windows, Version 9.2 (SAS Institute Inc. Cary, NC, USA).

\section{Results}

All GPs in this study were employed by the city of Turku. They were working in 11 primary healthcare centres in different parts of the city, and in the primary care emergency clinic. The number of full-time tenured GPs increased from 71 in 2001, to 74 in 2006 and 77 in 2010. In 2003, 2005, 2006 and 2008, the number of tenured GPs remained the same as in the previous year. In addition, a large number of locums were employed every year to cover for GPs on annual leave, study leave, and other leaves of absence; these locums were employed for different lengths of time and many worked part-time. Thus, during the years 2001-2010, an average of 135.6 individual GPs per year were employed by the city. Each GP worked 109 days per year on average and treated an average of 1003 individual patients annually.

During the years 2001-2010, a total of 1,816,457 face-to-face visits were made to the GPs, of which 166,059 visits were made by FA patients. The visits of the FA patients accounted for $9.1 \%$ (mean value) of all GP visits in primary healthcare. At the same time, FAs represented only $1.8 \%$ (mean value) of all patients (Table 1). The average number of individual patients was 73,096 per year, and of FA patients 1327 per year. FAs made on average 16,606 visits per year during the period covered by this study (Table 1 ).

In 2001, the total number of FA patients was 1415 , or $1.9 \%$ of all patients who used public healthcare services provided by GPs that year. The number of FAs varied between 1241 and 1415 during the subsequent 9 years (to 2010). The annual mean number of visits to a GP per FA varied between 12.3 and 12.8. The total annual number of FA patient visits went down from 17,627 in 2001 , to 15,276 in 2006, although there was a reversal in the downward trend in 2005, when patient visits rose to 16,140 from 15,886 in 2004. FA visits as a proportion of all GP visits varied between 8.5 and 9.8\%. Treatment plans were made for 73 of the patients listed as FAs in 2004 , i.e. for only $5.9 \%$ of all FA patients that year.

At the outset in 2001, FA visits as a proportion of all visits to GPs was 9.1\%. The GPs received information on their FAs between 2002 and 2005, and after these interventions, FA visits as a proportion of all visits to GPs decreased significantly in 2003 and even more so in 2006, compared with the situation in 2001. FA visits in 2003 had decreased from 9.1\% (2001) to 8.7\%, and in 2006 from $9.1 \%$ (2001) to $8.5 \%(p<0.0001$ for both comparisons). The number of FA visits was smallest in 2006, when it stood at 15276 visits (Table 1).

During the follow-up period 2007-2010, when there was no administrative information about FAs given to

Table 1 Total number of visits, number of FA visits, and proportion of FAs visits in 2001-2010

\begin{tabular}{|c|c|c|c|c|c|c|}
\hline Year & Number of all visits & Number of FA visits & $\begin{array}{l}\text { Proportion of FA } \\
\text { visits of all visits \% }\end{array}$ & Number of patients & Number of FAs & $\begin{array}{l}\text { Proportion of FAs } \\
\text { of all patients } \%\end{array}$ \\
\hline 2001 & 194,217 & 17,627 & 9.1 & 75,560 & 1415 & 1.9 \\
\hline 2002 & 186,341 & 16,898 & 9.1 & 73,930 & 1332 & 1.8 \\
\hline 2003 & 183,184 & 15,876 & 8.7 & 72,302 & 1292 & 1.8 \\
\hline 2004 & 180,007 & 15,886 & 8.8 & 71,840 & 1287 & 1.8 \\
\hline 2005 & 180,380 & 16,140 & 8.9 & 73,185 & 1301 & 1.8 \\
\hline 2006 & 178,987 & 15,276 & 8.5 & 73,208 & 1241 & 1.7 \\
\hline 2007 & 179,361 & 16,620 & 9.3 & 72,370 & 1330 & 1.8 \\
\hline 2008 & 182,394 & 17,393 & 9.5 & 73,860 & 1380 & 1.9 \\
\hline 2009 & 174,486 & 17,104 & 9.8 & 71,968 & 1338 & 1.9 \\
\hline 2010 & 177,100 & 17,239 & 9.7 & 72,738 & 1349 & 1.8 \\
\hline
\end{tabular}


the GPs, there was a significant $(p<0.0001$, Table 2$)$ increase in the proportion of FA visits when compared with the proportion of FA visits in 2006.

Between 2001 and 2006, the number of FA visits decreased by 2351 visits. The average number of all patient consultations per GP in 2006 was 1234.4, so this reduction corresponded to the annual workload of 2 GPs. There was a very low response to our request for GPs to draw up treatment plans for their patients listed as FAs in 2004; plans were made for only 73 patients, less than $6 \%$ of FAs in that year.

\section{Discussion}

In the city where this study was conducted, FAs comprised $1.8 \%$ of all patients; this percentage is consistent with other studies which report proportions ranging from $1.7-4.7 \%[1,6]$. There are studies in which the proportion of FAs was found to be considerably higher from $10.6 \%$ to as much as $15.4 \%[14,24]$. This can be explained by differences in defining an FA, and differences between healthcare systems. During the first decade of this millennium, the total number of GP consultations decreased in the city in question, and similar decreases happened over the same period elsewhere in Finland, too. Although the reasons for this phenomenon are unclear, it is possible that the overall number of GP consultations has gone down because individual consultations tend to be longer now than before, as patients' problems become more complex and more time-consuming to deal with [25].

In 2002, 2003 and 2005, GPs in the city's primary healthcare system received administrative information about their FA patients: their names and number of GP visits made by each one during the preceding year. This rather simple procedure seemed to reduce the number of FA patients' visits to a GP. Compared with the figure

Table 2 Changes in the proportion of FA visits of all visits over the period 2001-2010

\begin{tabular}{lllll}
\hline Years compared & RR & $95 \% \mathrm{Cl}$ & & $p$-value \\
\hline 2002 with 2001 & 0.99 & 0.978 & 1.03 & 0.9379 \\
2003 with 2001 & 0.95 & 0.93 & 0.98 & $<0.0001$ \\
2004 with 2001 & 0.97 & 0.95 & 0.99 & 0.0104 \\
2005 with 2001 & 0.99 & 0.97 & 1.01 & 0.1918 \\
2006 with 2001 & 0.94 & 0.92 & 0.96 & $<0.0001$ \\
2007 with 2006 & 1.09 & 1.06 & 1.11 & $<0.0001$ \\
2008 with 2006 & 1.12 & 1.09 & 1.14 & $<0.0001$ \\
2009 with 2006 & 1.15 & 1.12 & 1.17 & $<0.0001$ \\
2010 with 2006 & 1.14 & 1.12 & 1.17 & $<0.0001$ \\
\hline
\end{tabular}

Intervention in the form of individualized information to GPs on frequent attendance was provided in 2002, 2003, and 2005. An RR of more than 1.00 signifies that there was an increase in FA visits

RR Relative Risk, $\mathrm{Cl}$ Confidence Interval

* Statistical significance between years; Poisson's regression analysis for 2001 (17,627 FA consultations), the decrease in the annual consultation rate of FA patients was significant in both 2003 and 2006. When the administrative information was no longer provided, the FA consultation rate per year increased again, as seen by comparing the figure for 2006 with the figures for the four subsequent years (2007-2010). A systematic literature review conducted in 2008 concluded that there is no evidence that FAs' utilization of healthcare services can be reduced [26]. The results of our study, however, are more optimistic; the simple procedure of providing administrative information directly to GPs did seem to reduce FAs' consultation rates. In fact, the reduction in the consultation rates of FA patients from 2001 to 2006 corresponds to the annual workload of 2 GPs. This finding is in line with the conclusions of Heywood et al. [14].

The information about FAs was provided once annually in 2002, 2003 and 2005, to all GPs who were working in the city of Turku at the time of the information session, but the fluctuation in the number of individual GPs from year to year, and the low number of full-time GPs might influence the findings. The number of the full-time GPs was unchanged in 2003, 2005, 2006 and 2008. Locums are hardly the explanation for the decrease in FAs' visits in 2003 and 2006. In 2004, on the other hand, the number of full-time GPs changed which may partly explain why there was no reduction in FA patients' visit rates in 2005. Furthermore, no administrative information on FAs was provided in 2004, which may also have contributed to the slight reversal in 2005 in the overall downward trend. During this decade, the number of tenured GPs increased by six, and the number of locums varied. The effects of the fluctuations in the number of full-time GPs and the large number of medical officer locums are not known and cannot be analysed in this study setting.

The administrative information on FA patients was provided in the course of regular team meetings between the GPs and the chief medical officer; thus there was no parallel group of uninformed GPs to act as a control group. The method used was very simple. In the study of Bellón et al., GPs received 15 h' training about the issue of FA-patients, and this intervention, too, yielded a significant reduction in the frequency of FA consultations [21]. Our intervention to GPs was much simpler and considerably less time-consuming, as it took place once a year in the course of normal meeting.

GPs made only few treatment plans to FAs. It is impossible to say whether treatment plans would be helpful in improving the health or reducing the visit rate of FA patients.

The electronic patient record system used in the health care centres involved in this study does not have useful tools for enabling the GPs to monitor their work. 
This might be one reason why providing administrative information in face-to-face sessions turned out to be important. For example, the electronic patient record system does not allow for serial numbering of patient contacts during the year; such a feature would enable GPs to recognize instantly the patients making frequent visits.

The strength of the present study is the large amount of data on GP visits during 2001-2010, covering 1,816,457 appointments, including 166,059 appointments with FAs. Also, providing GPs with the administrative information was simple, quick, and easily repeated procedure. A weakness may be the fact that the administrative information provided was not methodologically standardized; it was incorporated into managerial routine. Another weakness was that we had no possibility to use a control group of GPs who had not received information on their FA patients; this methodological drawback arose from the realities of everyday management. The results need to be confirmed by further comparative studies.

\section{Conclusion}

Providing administrative information to GPs about their frequently attending patients, including their names and the frequency of their visits, yielded only a modest overall reduction in the number of frequent attenders over the period covered by the study. However, in two of the years (2003 and 2006), there were significant reductions in the total number of visits of FA patients, even though the numbers of FA patients themselves decreased only slightly. It thus seems that this simple intervention can reduce the annual number of visits by FAs to public healthcare centres, rate of frequent attenders was significantly reduced. It seems that such administrative information can reduce the number of annual visits by FA-patients in public healthcare centres, where GPs are working as a team and are led by one chief medical physician. To our knowledge, this is the first study to show that this kind of simple administrative information given by the chief medical officer to the GPs can significantly reduce the consultation rate of frequently attending patients.

\section{Acknowledgements}

We thank professor Ivar Sønbø Kristiansen (MD, PhD, MPH Institute of Health Management and Health Economics University of Oslo) and Virpi Rantanen (MD, PhD, adjunct professor in Obstetrics and Gynaecology at the University of Turku) for valuable comments to manuscript. Päivi Ovaskainen, PhD, provided help with literature about information management.

\section{Funding}

The study was supported by a government grant for the city of Turku, Healthcare Center in 2009 and 2010

\section{Availability of data and materials}

According to the Finnish law, the source data, which consists of individual patients' sensitive health data, is under professional secrecy, patient confidentiality and privacy regulations, and is available for scientific research purposes only subject to an approved application to the appropriate authorities (here the City of Turku, Healthcare Center). The authors will be available to assist in an application at request. Aggregated data can be obtained from the authors at request.

\section{Authors' contributions}

AKS collected the data and performed the drafting of the manuscript. AKS, TJV, SHL and PTR participated in the conception and design of the research, critically revising the manuscript for its intellectual content. AKS, TJV, SHL and PTR have read and approved of the final version.

\section{Ethics approval and consent to participate}

Not applicable. According to the Finnish law, register studies do not need Ethics approval, and consent is not required if access to data is provided by a competent authority. The medical record data used in the research has been obtained by the permission of the official authority competent to grant access, who has also evaluated the legality of providing and using the data in accordance with the applicable law. Here the relevant authority has been the City of Turku, Healthcare Center.

\section{Consent for publication}

Not applicable. According to the Finnish law, a consent to publish is not required. No individually identifiable results are included in the publication.

\section{Competing interests}

The authors declare that they have no competing interests.

\section{Publisher's Note}

Springer Nature remains neutral with regard to jurisdictional claims in published maps and institutional affiliations.

\section{Author details \\ ${ }^{1}$ Turku City Healthcare Center, Turku, Finland. ${ }^{2}$ Department of Biostatistics, Faculty of Medicine, University of Turku, Turku, Finland. ${ }^{3}$ Department of Psychiatry, University of Turku, Turku, Finland. ${ }^{4}$ Department of Psychiatry, Turku University Hospital, Turku, Finland. ${ }^{5}$ Department of Public Health, Faculty of Medicine, University of Turku, Turku, Finland. ${ }^{6}$ Turku Clinical Research Centre, Turku University Hospital, Turku, Finland.}

Received: 18 April 2017 Accepted: 17 August 2018

Published online: 28 August 2018

\section{References}

1. Jyväsjärvi S. Frequent attenders in primary health care: a cross-sectional study of frequent attenders' psychosocial and family factors, chronic diseases and reasons for encounter in a Finnish health Centre. PhD [dissertation]. Oulu: University of Oulu; 2001.

2. Savonius B. Frequent attendance in healthcare center of Espoo. Finn Med J. 1988;43:1718-20.

3. Koskela $\mathrm{T}-\mathrm{H}$. The prognostic risk factors for long term frequent use of the primary health care services. PhD [dissertation]. Kuopio: University of Kuopio; 2008.

4. Karlsson H, Lehtinen V, Joukamaa M. Frequent attenders of Finnish public primary health care: sociodemographic characteristics and physical morbidity. Fam Pract. 1994;11:424-30.

5. Cerney TA, Guy S, Jeffrey G. Frequent attenders in general practice: a retrospective 20-years follow-up study. Br J Gen Pract. 2001;51:567-9.

6. Andersson SO, Mattsson B, Lynoe N. Patients frequently consulting general practitioners at primary healthcare Centre in Sweden - a comparative study. Scand J Soc Med. 1995;23:251-7.

7. Gill D, Sharpe M. Frequent consulters in general practice: a systematic review of studies of prevalence, associations and outcome 1999. J Psychosom Res. 1999;47:115-30.

8. Westhead JN. Frequent attenders in general practice: medical, psychological and social characteristics. J R Coll Gen Pract. 1985:35:337-40.

9. Neal R, Heywood P, Morley S. Frequent attenders' consulting patterns with general practitioners. Br J Gen Pract. 2000;50:972-6.

10. Karlsson H, Joukamaa M, Lahti I, Lehtinen V, Kokki-Saarinen T. Frequent attender profiles: different clinical subgroups among frequent attender patients in primary care. J Psychosom Res. 1997;42:157-66. 
11. Backett EM, Heady JA, Evans JCG. Studies of a general practice (II) the doctor's job in an urban area. BMJ. 1954;1:109-15.

12. Vedsted $\mathrm{P}$, Christensen MB. Frequent attenders in general practice care: a literature review with special reference to methodological considerations. Public Health. 2005;119:118-37.

13. Neal R, Dowell A, Heywood P, Morley S. Frequent attenders: who needs treatment? Br J Gen Pract. 1996;46:131-2.

14. Heywood PL, Blackie GC, Cameron IH, Dowell AC. An assessment of the attributes of frequent attenders to general practice. Fam Pract. 1998;15: 198-204.

15. Baez K, Aiarzaguena JM, Grandes G, Pedrero E, Aranguren J, Retolaza A. Understanding patient-initiated frequent attendance in primary care: a casecontrol study. Br J Gen Pract. 1998;48:1824-7.

16. Foster A, Jordan K, Croft P. Is frequent attendance in primary care diseasespecific? Fam Pract. 2006:23:444-52

17. Jyvasjarvi S, Keinanen-Kiukaanniemi S, Vaisanen E, Larivaara P, Kivela SL. Frequent attenders in a Finnish health Centre: morbidity and reasons for encounter. Scand J Prim Health Care. 1998;16:141-8.

18. Savageau JA, McLoughlin M, Ursan A, Bai Y, Collins M, Cashman SB. Characteristics of frequent attenders at a community health center. J Am Board Fam Med. 2006;19:265-75.

19. Bergh $\mathrm{H}$, Marklund B. Characteristics of frequent attenders in different age and sex groups in primary health care. Scand J Prim Health Care. 2003;21: $171-7$.

20. Vedsted P, Fink P, Sorensen HT, Olesen F. Physical, mental and social factors associated with frequent attendance in Danish general practice. A population-based cross-sectional study. Soc Sci Med. 2004;59:813-23.

21. Bellón JA, Rodríguez-Bayón A, de Dios Luna J, Torres-González F. Successful $\mathrm{GP}$ intervention with frequent attenders in primary care. Br J Gen Pract. 2008:58:324-30.

22. Jiwa M. Frequent attenders in general practice: an attempt to reduce attendance. Fam Pract. 2000;17:248-51.

23. Engeström $Y$. Innovative learning in work teams: analyzing cycles of knowledge creation in practice. In: Engeström Y, Miettinen R, Punamäki RL, editors. Perspectives on activity theory. Cambridge: Cambridge University Press; 1998. p. 377-404.

24. Smits F, Brouwer HJ, Riet G, van Weert $\mathrm{H}$. Epidemiology of frequent attenders: a 3-years historic cohort study comparing attendance, morbidity and prescriptions of one-year and persistent frequent attenders. BMC Public Health. 2009;9:36.

25. Ovaskainen PT, Rautava PT, Ojanlatva A, Päkkilä JK, Päivärinta RM. Analysis of primary health care utilisation in South-Western Finland--a tool for management. Health Policy. 2003;66:229-38.

26. Smits FT, Wittkampf KA, Schene AH, Bindels PJ, Van Weert HC. Intervention on frequent attenders in primary care, a systematic literature review. Scand J Prim Health Care. 2008;26:111-6.

Ready to submit your research? Choose BMC and benefit from:

- fast, convenient online submission

- thorough peer review by experienced researchers in your field

- rapid publication on acceptance

- support for research data, including large and complex data types

- gold Open Access which fosters wider collaboration and increased citations

- maximum visibility for your research: over $100 \mathrm{M}$ website views per year

At BMC, research is always in progress.

Learn more biomedcentral.com/submissions 